\title{
Growth and body proportions in congenital adrenal hyperplasia
}

\author{
M C YOUNG, J RIBEIRO, AND I A HUGHES \\ Department of Child Health, University of Wales College of Medicine, Cardiff
}

SUMmaRY Total height, sitting height, and subischial leg length were measured in 27 patients (19 girls and eight boys aged $4 \cdot 3-21 \cdot 1$ years) with congenital adrenal hyperplasia to determine the influence of chronic hyperandrogenaemia on body proportions. Proportions were normal in 24 patients with classical congenital adrenal hyperplasia who had received steroid treatment since birth, but one of three patients with non-classical (late onset) congenital adrenal hyperplasia had a disproportionately large trunk. Eleven patients with classical congenital adrenal hyperplasia had completed growth, of whom seven had height standard deviation (SD) scores for chronological age less than zero, and one had extremely short stature (SD score -3.25). In 13 patients who were still growing, nine had height SD scores for chronological age of less than zero despite having mean (SD) advances in bone age over chronological age of $1.64(1.68)$ years. Height SD scores for bone age were less than 0 in all 13 patients, indicating a loss of height despite advanced skeletal maturation.

Doses of glucocorticoid that permit mild chronic or intermittent hyperandrogenaemia also seem to be associated with mild growth retardation. An adult height below average may be an inevitable consequence for many patients with congenital adrenal hyperplasia receiving conventional glucocorticoid treatment.

Growth in stature is an important component in assessing the outcome of treatment in patients with congenital adrenal hyperplasia. Growth velocity provides a valuable guide to the adequacy of control during infancy and childhood, and the attainment of normal adult height is a principle aim of treatment. ${ }^{1}$ Though this may sometimes occur without treatment, ${ }^{2}$ diminished final height as a result of premature epiphyseal fusion caused by chronic hyperandrogenaemia is the usual outcome in untreated congenital adrenal hyperplasia. ${ }^{3}$ Below average final height is common even with treatment ${ }^{34}$; this may result from mild or intermittent hyperandrogenaemia associated with inadequate adrenal suppression, or from the direct growth suppressive effect of excessive treatment with glucocorticoids. ${ }^{56}$

Increased plasma concentrations of testicular testosterone in boys and adrenal androgens in girls contribute to the adolescent growth spurt, mainly through their effect on truncal growth. ${ }^{78}$ Precocious puberty is characterised by a decrease in final height, but a disproportionate increase in the size of the trunk. ${ }^{9}$ Hyperandrogenaemia in congenital adrenal hyperplasia is present from early fetal life, and to a variable extent postnatally depending on both the age at diagnosis and the degree of therapeutic control. Inadequate control can lead to pseudoprecocious puberty in boys and true precocious puberty in both sexes. ${ }^{1}$ These factors suggest that growth may be disproportionate in congenital adrenal hyperplasia. This paper reports the first systematic study of growth and body propor-

Table 1 Classification of patients according to type of congenital adrenal hyperplasia

\begin{tabular}{|c|c|c|c|c|}
\hline & \multicolumn{2}{|c|}{ Classical adrenal hyperplasia } & \multirow{2}{*}{$\begin{array}{l}\text { Non-classical } \\
\text { adrenal } \\
\text { hyperplasia } \\
\text { (group 3) }\end{array}$} & \multirow[t]{2}{*}{ Total } \\
\hline & $\begin{array}{l}\text { Group 1 } \\
\text { (complete } \\
\text { growth) }\end{array}$ & $\begin{array}{l}\text { Group } 2 \\
\text { (incomplete } \\
\text { growth) }\end{array}$ & & \\
\hline Boys & 3 & 5 & 0 & 8 \\
\hline Girls & 8 & 8 & 3 & 19 \\
\hline Total & 11 & 13 & 3 & 27 \\
\hline
\end{tabular}


Table 2 Auxological data

\begin{tabular}{|c|c|c|c|c|c|c|c|c|c|c|c|c|c|c|}
\hline \multirow{2}{*}{\multicolumn{2}{|c|}{$\begin{array}{l}\text { Case } \\
\text { No }\end{array}$}} & \multirow{2}{*}{$\begin{array}{l}\text { Height } \\
\text { (cm) }\end{array}$} & \multirow{2}{*}{$\begin{array}{l}\text { Sitting } \\
\text { height } \\
(\mathrm{cm})\end{array}$} & \multirow{2}{*}{$\begin{array}{l}\text { Subischial } \\
\text { leg length } \\
(\mathrm{cm})\end{array}$} & \multirow{2}{*}{$\begin{array}{l}\text { Chrono- } \\
\text { logical } \\
\text { age } \\
\text { (years) }\end{array}$} & \multirow{2}{*}{$\begin{array}{l}\text { Bone age } \\
\text { (years) }\end{array}$} & \multirow{2}{*}{$\begin{array}{l}\text { Bone age } \\
\text { minus } \\
\text { chrono- } \\
\text { logical } \\
\text { age }\end{array}$} & \multicolumn{3}{|c|}{ Chronological age } & \multicolumn{3}{|c|}{ Bone age } & \multirow[t]{2}{*}{$F^{*}$} \\
\hline & & & & & & & & $\begin{array}{l}\text { Height } \\
S D \\
\text { score }\end{array}$ & $\begin{array}{l}\text { Sitting height } \\
\text { SD score }\end{array}$ & $\begin{array}{l}\text { Subischial } \\
\text { leg length } \\
S D \text { score }\end{array}$ & $\begin{array}{l}\text { Height } \\
S D \\
\text { score }\end{array}$ & $\begin{array}{l}\text { Sitting height } \\
\text { SD score }\end{array}$ & $\begin{array}{l}\text { Subischial } \\
\text { leg length } \\
\text { SD score }\end{array}$ & \\
\hline \multicolumn{15}{|c|}{ Group 1: } \\
\hline 1 & & 153.9 & $82 \cdot 2$ & $71 \cdot 7$ & $18 \cdot 3$ & Adult & - & -1.38 & $-1 \cdot 72$ & -0.72 & $-1 \cdot 38$ & $-1 \cdot 77$ & -0.72 & -1.05 \\
\hline 2 & & $151 \cdot 5$ & $80 \cdot 5$ & $71 \cdot 0$ & $13 \cdot 2$ & Adult & - & -0.88 & -0.97 & -0.51 & -1.78 & $-2 \cdot 32$ & -0.90 & -0.46 \\
\hline 3 & & $158 \cdot 5$ & $87 \cdot 1$ & $71 \cdot 4$ & $14 \cdot 0$ & Adult & - & -0.35 & $0 \cdot 27$ & $-0 \cdot 71$ & -0.62 & $-0 \cdot 19$ & -0.79 & 0.98 \\
\hline 4 & & 159.7 & 88.7 & $71 \cdot 0$ & 17.9 & Adult & - & -0.42 & 0.32 & -0.90 & -0.42 & 0.32 & -0.90 & 1.22 \\
\hline 5 & , & 156.0 & 88.6 & 69.4 & 20.7 & Adult & - & -1.03 & -0.35 & $-1 \cdot 30$ & -1.03 & -0.35 & $-1 \cdot 30$ & 0.95 \\
\hline 6 & $v^{\prime}$ & 136.9 & $76 \cdot 4$ & $60 \cdot 5$ & $20 \cdot 3$ & Adult & - & $-4 \cdot 22$ & -3.65 & -3.59 & $-4 \cdot 22$ & -3.65 & -3.59 & -0.06 \\
\hline 7 & & $167 \cdot 8$ & $87 \cdot 3$ & $80 \cdot 5$ & $21 \cdot 1$ & Adult & - & 0.93 & $-0 \cdot 13$ & 1.54 & 0.93 & $-0 \cdot 13$ & 1.54 & -1.67 \\
\hline 8 & & 152.1 & $84 \cdot 2$ & 67.9 & $16 \cdot 5$ & Adult & - & -1.68 & $-1 \cdot 13$ & -1.69 & -1.68 & $-1 \cdot 13$ & -1.69 & $0 \cdot 56$ \\
\hline 9 & & $184 \cdot 0$ & 97.6 & $86 \cdot 4$ & $14 \cdot 8$ & Adult & - & 2.32 & 2.44 & 1.60 & 1.40 & $1 \cdot 24$ & $1 \cdot 24$ & 0.84 \\
\hline 10 & & 175.6 & 94.9 & $80 \cdot 7$ & 16.8 & Adult & - & 0.20 & 0.65 & -0.08 & $0 \cdot 14$ & 0.04 & $-0 \cdot 12$ & 0.73 \\
\hline 11 & & 168.7 & $90 \cdot 3$ & $78 \cdot 4$ & $20 \cdot 3$ & Adult & - & -0.90 & -0.97 & -0.67 & -0.90 & -0.97 & -0.67 & -0.30 \\
\hline \multicolumn{15}{|c|}{ Group 2: } \\
\hline 12 & & $91 \cdot 5$ & $52 \cdot 8$ & $38 \cdot 7$ & 3.9 & $4 \cdot 0$ & $0 \cdot 1$ & -2.07 & $-2 \cdot 44$ & -1.02 & -2.07 & -2.44 & -1.02 & -1.42 \\
\hline 13 & & 143.4 & 76.5 & 66.9 & $12 \cdot 0$ & 13.7 & 1.8 & -1.02 & -0.87 & -0.79 & $-2 \cdot 55$ & -2.78 & -1.82 & -0.08 \\
\hline 15 & & 155.7 & 81.0 & 74.7 & 13.6 & $13 \cdot 7$ & 0 & -0.53 & -1.29 & 0.23 & -0.53 & -1.29 & 0.23 & -1.52 \\
\hline 16 & & $115 \cdot 2$ & $64 \cdot 5$ & $50 \cdot 7$ & $8 \cdot 1$ & 8.6 & 0.5 & -1.71 & -1.49 & -1.41 & $-2 \cdot 17$ & -1.84 & -1.82 & -0.08 \\
\hline 17 & & $142 \cdot 7$ & 76.7 & $66 \cdot 0$ & $15 \cdot 7$ & $15 \cdot 3$ & -0.4 & $-3 \cdot 25$ & -3.49 & $-2 \cdot 18$ & $-3 \cdot 23$ & -3.44 & $-2 \cdot 18$ & $-1 \cdot 31$ \\
\hline 18 & & 155.0 & $83 \cdot 3$ & $71 \cdot 7$ & $13 \cdot 0$ & $14 \cdot 2$ & $1 \cdot 3$ & $-0 \cdot 30$ & $-0 \cdot 15$ & -0.33 & -0.93 & -0.98 & -0.67 & $0 \cdot 18$ \\
\hline 19 & & 149.0 & 82.2 & $66 \cdot 8$ & 12.9 & $15 \cdot 3$ & 2.5 & $-1 \cdot 30$ & -0.47 & -0.51 & -2.04 & -1.69 & -1.97 & 0.04 \\
\hline 20 & & 96.5 & $57 \cdot 8$ & $38 \cdot 7$ & $4 \cdot 3$ & 3.6 & 0.7 & $-1 \cdot 19$ & -0.91 & $-1 \cdot 90$ & -0.34 & 0.09 & -0.72 & 0.99 \\
\hline 21 & & 123.8 & 68.6 & $55 \cdot 2$ & $5 \cdot 8$ & $11 \cdot 3$ & $5 \cdot 5$ & 1.79 & 1.59 & 1.26 & $-2 \cdot 86$ & -2.46 & $-2 \cdot 88$ & 0.33 \\
\hline 22 & & $112 \cdot 5$ & $62 \cdot 5$ & 50.0 & 5.4 & 9.0 & 3.7 & 0.21 & $-0 \cdot 38$ & 0.66 & $-3 \cdot 18$ & $-3 \cdot 33$ & $-2 \cdot 72$ & -1.04 \\
\hline 23 & & $162 \cdot 3$ & $86 \cdot 2$ & $76 \cdot 1$ & 13.6 & 16.6 & 3.0 & 0.90 & $1 \cdot 16$ & $0 \cdot 58$ & -1.69 & -1.84 & $-1 \cdot 17$ & 0.58 \\
\hline 24 & & $117 \cdot 4$ & 67.5 & 49.9 & $5 \cdot 2$ & $7 \cdot 4$ & $2 \cdot 2$ & 1.92 & $2 \cdot 02$ & 0.96 & -1.06 & -0.35 & $-1 \cdot 51$ & 1.06 \\
\hline \multicolumn{15}{|c|}{ Group 3: } \\
\hline 25 & & $151 \cdot 7$ & $85 \cdot 0$ & $66 \cdot 7$ & $12 \cdot 7$ & Adult & - & -0.85 & $0 \cdot 64$ & -1.46 & -1.75 & $-0 \cdot 65$ & -1.95 & $2 \cdot 10$ \\
\hline 26 & & 148.9 & $79 \cdot 3$ & $69 \cdot 6$ & $12 \cdot 3$ & 13.5 & 1.20 & $-0 \cdot 10$ & -0.39 & -0.33 & -1.63 & -1.79 & -1.08 & -0.06 \\
\hline 27 & & 111.6 & 62.9 & 48.7 & $5 \cdot 6$ & 8.8 & 3.24 & 0.03 & 0.00 & 0.39 & $-3 \cdot 23$ & $-2 \cdot 61$ & $-2 \cdot 71$ & -0.39 \\
\hline
\end{tabular}

*F=function-sitting height SD score (chronological age) minus subischial leg length SD score (chronological age).

tions in a group of patients with congenital adrenal hyperplasia.

\section{Patients and methods}

Twenty seven patients (19 girls and eight boys aged between 4.3 and $21 \cdot 1$ years) with congenital adrenal hyperplasia were studied. All had 21-hydroxylase deficiency except for one (case 12) who had 11 $\beta$ hydroxylase deficiency. Patients were classified into three groups according to the type of congenital adrenal hyperplasia and their stage of growth (table 1). Groups 1 and 2 had received steroid treatment since infancy, initially as hydrocortisone 15-20 $\mathrm{mg} / \mathrm{m}^{2} /$ day in divided doses, and later in adolescence as dexamethasone $0 \cdot 25-0.75 \mathrm{mg} /$ day in single or divided doses. Glucocorticoid doses were adjusted individually according to measurements of plasma and saliva adrenal androgens and 17-hydroxyprogesterone concentrations that were determined at periodic clinic visits, and regular assessments of growth velocity and bone age. ${ }^{1}$ Treatment adjustments were made more recently using daily steroid profiles as an additional measurement. ${ }^{10}$ There were three patients in group 3 with non-classical (late onset) congenital adrenal hyperplasia. One (case 25) was untreated at the time of the study, case 27 had been treated for less than three months, and case 26 had received hydrocortisone for five years.

Total height and sitting height were measured in each patient by the same observer (JR) using a Harpenden stadiometer and sitting height table. Subischial leg length was calculated by subtracting sitting height from height. Standard deviation (SD) scores for height and subischial leg length were calculated for chronological age and bone age using published tables. ${ }^{11} 12$ Bone age was determined by a single observer (JR) according to the TannerWhitehouse method. ${ }^{13}$

\section{Results}

Data on growth and bone age for the three groups are shown in table 2 .

BONE AGE

All the patients in group 1 had completely fused epiphyses consistent with an adult bone age. Bone age was in advance of chronological age in all but one patient in group 2 . The mean (SD) increase (bone age-chronological age) was $1.6(1.7)$ years, indicating mild chronic hyperandrogenaemia. All 


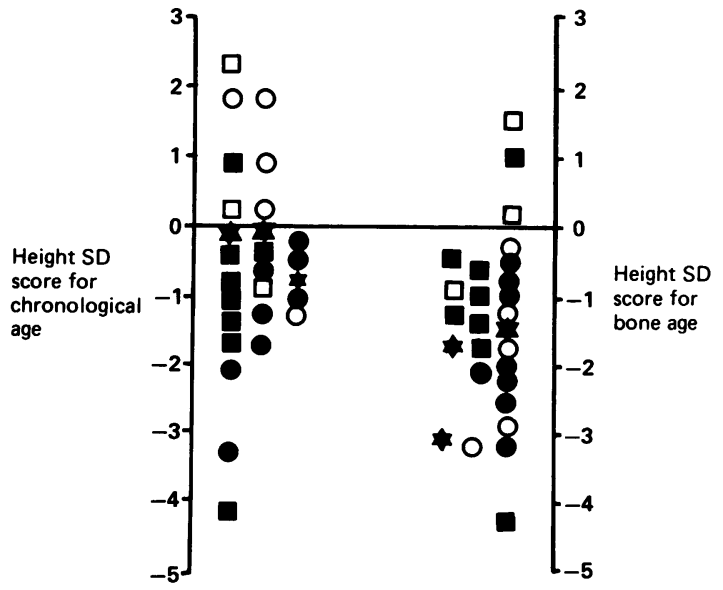

Fig 1 Height SD scores, for chronological age and bone age, for the three groups. Solid symbols=girls, open symbols = boys, asterisks $=$ late onset cases.

three patients with late onset congenital adrenal hyperplasia (group 3) had advanced bone ages, and case 25 had attained adult maturity.

\section{HEIGHT}

Fig 1 shows height SD scores for both chronological and bone ages for all patients. Only three patients in group 1 had height SD scores for chronological age greater than zero; the mean (SD) score for this group, who had completed their growth, was -1.69 (1.56). Parental heights were available for only

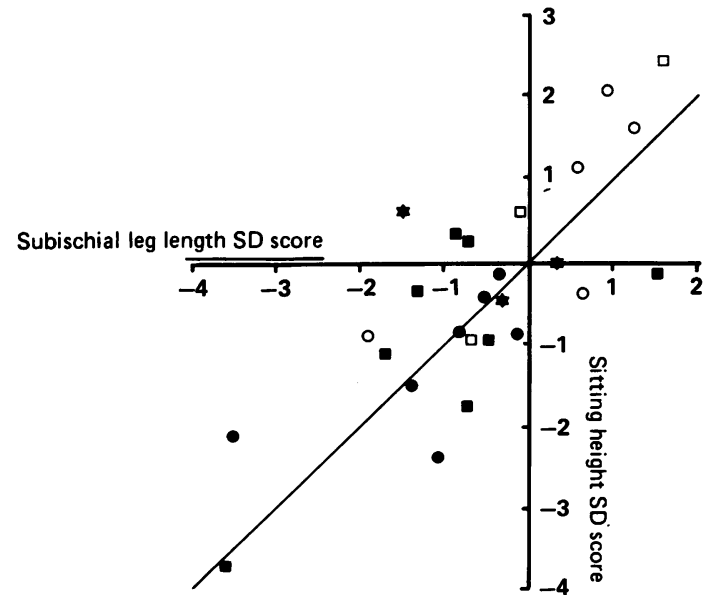

Fig 2 Body proportions expressed as SD scores for sitting height and subischial leg length according to chronological age. Solid symbols $=$ girls, open symbols $=$ boys, asterisks $=$ late onset cases. seven patients in this group; the mean paternal height $(172.4 \mathrm{~cm})$ and maternal height $(166.1 \mathrm{~cm})$ were not significantly different from the normal population.

Four patients in group 2 had height SD scores for chronological age greater than zero. When height SD score was calculated according to bone age, however, the scores were all less than zero indicating a considerable loss of height for the degree of skeletal maturity.

All the patients in group 3 had normal height SD scores for chronological age, but case 25 (whose epiphyses had already fused) will be a short adult. Height SD scores for bone age were all negative.

\section{BODY PROPORTIONS}

SD scores for sitting height and subischial leg length for all patients are shown in fig 2 (for chronological age and fig 3 (for bone age). The degree of proportionality of a subject may be assessed by comparing these values; in a perfectly proportioned individual the values will be equal even though the actual measurements may differ. This is indicated by the diagonal lines in figs 2 and 3 and the line of perfect proportionality in fig 4 . In a healthy population the difference between the values, which may be expressed as the function-sitting height $\mathrm{SD}_{-}$

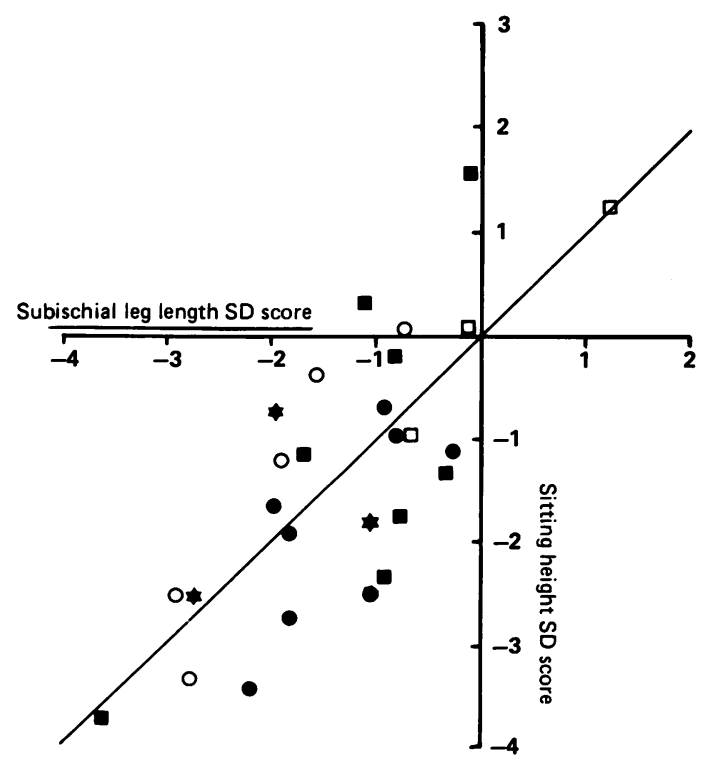

Fig 3 Body proportions expressed as SD scores for sitting height and subischial leg length according to bone age. Solid symbols = girls, open symbols =boys, asterisks=late onset cases. 


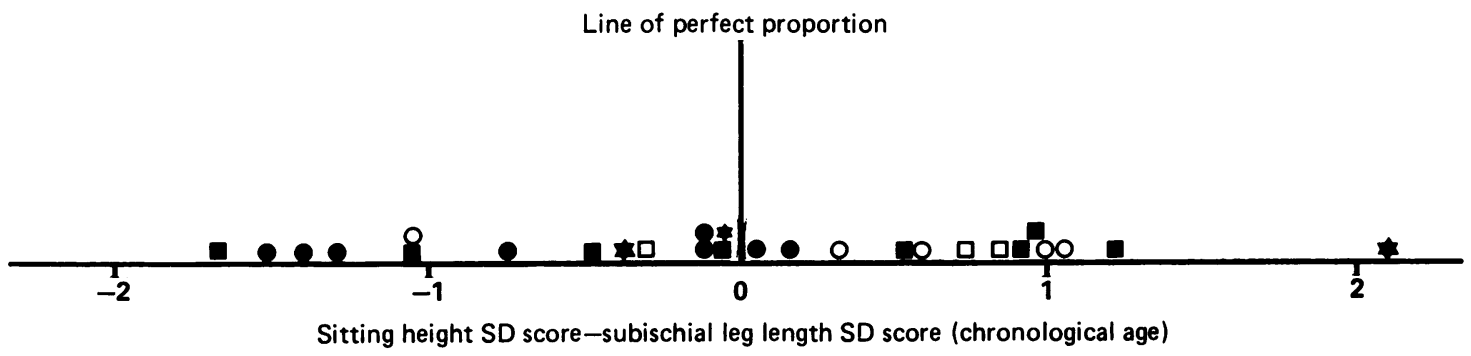

Fig 4 Differences between sitting height SD scores and subischial leg length SD scores for all patients. Solid symbols=girls, open symbols $=$ boys, asterisks $=$ late onset cases.

score for chronological age minus the subischial leg length SD score for chronological age-would have a normal distribution with a mean of zero and standard deviation of 1 . Disproportionality, implying an abnormal association between trunk and leg length, might therefore be defined as a function score of more than +2 or less than -2 . Sitting height SD scores and subischial leg length SD scores were generally reduced (negative), especially for bone age, and the impression that the values for patients in all three groups were scattered equally around the diagonal line (figs 2 and 3), was confirmed by the symmetrical distribution of function scores about the zero point, with a mean (SD) value for all patients of $0.02(1.00)$ (fig 4). Similar results were obtained when each group was analysed separately. Body proportions were therefore normal in all patients except for one (case 25), who had a disproportionately large trunk (function score $+2 \cdot 10$ ).

\section{Discussion}

Congenital adrenal hyperplasia is associated with hyperandrogenaemia during both prenatal and postnatal life. Plasma testosterone and androstenedione concentrations of $22 \mathrm{nmol} / \mathrm{l}$ and $216 \mathrm{nmol} / 1$, respectively, (adult reference ranges for men 10-30 and $4.4-10.6 \mathrm{nmol} / \mathrm{l}$, respectively) have been recorded in a female fetus with congenital adrenal hyperplasia of 22 weeks' gestation (unpublished observation).

Treatment aims to suppress the adrenal production of excess androgens, thereby allowing normal growth and development. Measurements of concentrations of adrenal steroids in plasma and saliva, in addition to monitoring growth, are important indices of therapeutic control, and treatment aims to keep these within the normal range. ${ }^{1}$

Patients in group 2 were carefully monitored and treated with adequate doses of glucocorticoids, yet they showed an increase in bone age over chronolo- gical age as a result of mild chronic or intermittent hyperandrogenaemia. Similar treatment regimens were used for patients in group 1 who had fused epiphyses at the time of the study. Neither group, however, showed evidence of body disproportion as a result of excessive truncal growth. This was observed in only one girl with untreated late onset congenital adrenal hyperplasia in whom skeletal maturation was extremely advanced; plasma testosterone and androstenedione concentrations were 18 and $70 \mathrm{nmol} / \mathrm{l}$, respectively.

The results of this study suggest that body proportions are usually normal in congenital adrenal hyperplasia despite chronic or intermittent hyperandrogenaemia, except perhaps where severe hyperandrogenaemia has been present in the postnatal period for some considerable time. In keeping with the results of other studies ${ }^{2-5} 1415$ final height was below average in patients in group 1 who had completed their growth. Three of the 11 patients were above average height, while the remainder showed varying degrees of shortness. In seven of these patients (not including case 6), height outcome could be judged in comparison with parental heights; five achieved final heights less than the mid parental height and in two cases this was greater than $-2 \mathrm{SD}$ below the latter.

Height in those still growing (group 2) was suboptimal, particularly when height SD scores were related to bone age. Loss of height was apparently less in boys than in girls (height SD score for chronological age $0.73(1.28)$ and $-1.36(0.97)$, respectively), but boys had a disproportionate advance in bone age ((bone age-chronological age); for boys $2.71(2.27)$, and girls $0.80(0.98))$. This height advantage disappeared when height SD score was expressed for bone age (fig 1 ). The greater advance in bone age for boys may be the result of a number of factors. The diagnosis is generally established later in boys than in girls, by which time 
bone age is already advanced. The clinical signs of mild hyperandrogenaemia are likely to be less acceptable in girls.

Previous studies of growth in congenital adrenal hyperplasia have often attributed poor outcome to inadvertent overtreatment with steroids, particularly during infancy when growth retardation may not be followed by catch up growth after dose reduction. ${ }^{45}$ High dose regimens based on the results of early studies, ${ }^{16}$ the use of insensitive measurements of control, ${ }^{110}$ and excessive steroid treatment at the time of diagnosis and during intercurrent illness ${ }^{5}$ are all factors contributing to suppression of growth. The resulting loss in height has generally been associated with a delay in skeletal maturation. ${ }^{15}$ Patients in group 2 in this study were treated with lower doses of steroid in general, and more sensitive measurements of control were used for monitoring treatment. Consequently bone age was usually in advance of chronological age and yet the outcome for height was still unsatisfactory in some patients.

Growth is extremely sensitive to exogenous steroids $^{6}{ }^{17}$ and even a small amount of steroid given in excess of physiological requirements may be detrimental. ${ }^{18}$ Glucocorticoids can affect the spontaneous secretion of growth hormone $e^{19}$ and its response to provocative stimulation, ${ }^{20}$ but steroid induced inhibition of growth is probably mediated through a more direct action on epiphyseal cartilage metabolism. ${ }^{6}$ The results of this study suggest that doses of glucocorticoid that permit a mild advance in skeletal maturation may also be sufficient to restrict growth.

Perhaps some loss of height in patients with congenital adrenal hyperplasia may be inevitable with the treatment regimens currently used. Nevertheless, the potential loss of height can be minimised by ensuring that only the smallest dose of glucocorticoid necessary is used, that mineralocorticoid treatment is given to patients with raised plasma renin activity, and that sensitive biochemical measures of therapeutic control are used to supplement the standard criteria of clinical control.

\footnotetext{
References

1 Hughes IA. Management of congenital adrenal hyperplasia. Arch Dis Child 1988:63:1399-404.
}

2 Bergstrand CG. Growth in congenital adrenal hyperplasia. Acta Paediatr Scand 1966;55:463-72.

${ }^{3}$ Brook CGD, Zachmann M, Prader A, Murset G. Experience with long-term therapy in congenital adrenal hyperplasia. J Pediatr 1974;85:12-9.

4 Dimartino-Nardi J, Stoner E, O`Connell A, New MI. The effect of treatment on final height in classical congenital adrenal hyperplasia. Acta Endocrinol 1986;279(suppl):305-13.

5 Rappaport R, Cornu G, Royer P. Statural growth in congenital adrenal hyperplasia treated with hydrocortisone. J Pediatr 1968;73:760-6.

${ }^{6}$ Hughes IA. Steroids and growth. $\mathrm{Br}$ Med J 1987;295:683-4.

7 Tanner JM, Whitehouse RH, Hughes PCR, Carter BS. Relative importance of growth hormone and sex steroids for the growth at puberty of trunk length, limb length, and muscle width in growth hormone deficient children. J Pediatr 1976;39:1000-8.

8 Marshall WA. Human growth and its disorders. London: Academic Press, 1977.

9 Martinez L, Preece MA, Grant DB. Body proportions in precocious puberty. Acta Paediatr Scand 1984;73:185-8.

10 Young MC, Robinson JA, Read GF, Riad-Fahmy D, Hughes IA. 170H-progesterone rhythms in congenital adrenal hyperplasia. Arch Dis Child 1988;63:617-23.

"Smith DW. Growth and its disorders. In: Schaffer JA, Markowitz M, eds. Major problems in clinical paediatrics. Vol 15. London: W B Saunders, 1977.

12 Tanner JM, Whitehouse RH. Standards for sitting height and sub-ischial leg-length from birth to maturity: British children 1978. Hertford: Castlemead Publications, 1979.

13 Tanner JM, Whitehouse RH, Marshall WA, Healy MJR, Goldstein $\mathrm{H}$. Assessment of skeletal maturity and prediction of adult height (TW2 method). London: Academic Press, 1975.

14 Clayton GW. Patterns of growth from birth to maturity in infants and children with congenital adrenal hyperplasia. Acta Endocrinol 1986;279(suppl):295-304.

15 Bailey CC, Komrower GM. Growth and skeletal maturation in congenital adrenal hyperplasia. Review of 20 cases. Arch Dis Child 1974;49:4-7.

16 Grumbach MM, Wilkins L. The pathogenesis and treatment of virilizing adrenal hyperplasia. Pediatrics 1956;17:418-27.

17 Moell C, Aronson AS, Selvik G. Growth in rabbits during alternate day cortisone injections: near normal growth on days without cortisone. Acta Paediatr Scand 1988;77:693-8.

${ }^{18}$ Sobel EH, Hahm SYE. Compensatory growth after HLA-typing revelation of incorrect diagnosis of 21-hydroxylase deficiency. Acta Endocrinol 1986:279(suppl):290-3.

19 Bierich JR. Serum growth hormone levels in provocative tests and during nocturnal spontaneous secretion: a comparative study. Acta Paediatr Scand 1987;337(suppl):48-59.

20 Stempfel RS, Sheikholislam BM, Lebovitz HE, Allen E, Franks RC. Pituitary growth hormone suppression with low dosage, long active corticoid administration. J Pediatr 1968;75:767-73.

Correspondence and requests for reprints to Professor IA Hughes, Department of Paediatrics, University of Cambridge School of Clinical Medicine, Addenbrooke's Hospital, Level 8, Hills Road, Cambridge CB2 2QQ.

Accepted 27 June 1989 